\title{
¿CÓMO QUIERE DIOS SER SERVIDO? EL SERVICIO DE DIOS EN LA FILOSOFÍA DE LA RELIGIÓN DE KANT*
}

\author{
Bernd DÖRFLINGER \\ Universidad de Tréveris
}

RESUMEN: Dios es postulado desde la razón práctica como objeto de fe, garante del bien supremo. Los deberes aparecen entonces también en cuanto mandamientos que indican cómo Él debe ser servido. Según la religión puramente moral y racional, sólo la buena conducta moral es directamente agradable a Dios, y no las acciones extras que las religiones históricas ordenan como siendo de servicio divino. Pero si eliminamos de ellas su antropomorfismo práctico (casi inevitable en los creyentes), podrian tener, para algunos que lo necesitaran, un valor simbolico en cuanto medios sensibles de moralización, por ejemplo la oración.

Investigar, sobre la base de la filosofía de Kant, la cuestión de cómo quiere Dios que nosotros le sirvamos, no es algo obvio. Pues según su más famosa obra, la Crítica de la razón pura, el concepto de Dios pertenece a las ideas ilusorias, es decir, a las ilusiones hacia cuyos objetos ciertamente se dirige una y otra vez la intención cognoscitiva de la razón, pero siempre inútilmente. Que la intención cognoscitiva de la razón teórica en relación a Dios es en principio irrealizable, ése es el resultado del apartado sobre la imposibilidad de toda demostración de Dios. Sobre todo por eso, Kant fue llamado por Moses Mendelssohn el «aplástalo-todo". Y de hecho, el carácter limitador de las pretensiones del conocimiento que tiene la Crítica de la razón pura se encuentra cerca del agnosticismo; ciertamente no del ateísmo, porque en ese caso se tendría que demostrar la no existencia de Dios - lo que es tan imposible de demostrar como su existencia-, pero sí una agnóstica abstención del juicio.

Ahora bien, según Kant a pesar de la incognoscibilidad para nosotros de algunas cosas no está excluida necesariamente la existencia de las mismas, pues

* Traducido del alemán por Jacinto Rivera de Rosales, revisado por Pedro Jesús Teruel. 
tampoco se puede afirmar que con la esfera de las cosas que aparecen en la intuición se agote la esfera de las cosas en general. En el caso del concepto de Dios, por una parte hay algo pensado, una cosa del pensamiento, pues de hecho en algo se piensa cuando se piensa en Dios, en algo todopoderoso y omnisciente, y dado que paede ser pensado sin contradicción, cumple con la condición mínima de la racionalidad teórica, y obtiene de Kant la distinción (ciertamente no muy alta) de que no es imposible que la cosa exista. Por otra parte hay, por así decir, un espacio para la existencia de esa cosa, pues justamente el concepto de la cosa fenoménica no coincide con el de la cosa en general; ese espacio no es accesible al saber, pero es conquistable por otro modo de asentimiento. El famoso dictum de Kant, que es apenas evitable en este lugar, reza así: "Tuve por tanto que suprimir el saber para hacer espacio a la fe" $(\mathrm{B} X X X)^{1}$.

Sobre la base de la teoría del conocimiento de la metafísica crítica de la Crítica de la razón pura, este lugar está ciertamente bastante vacío. Es muy dudoso, en efecto, que se puede engendrar una fe sin otro punto de apoyo que la base de la mínima modalidad de la no imposibilidad de Dios. Por lo demás, según el mismo Kant la fe es un asentimiento en el modo de la certeza subjetiva que apenas puede basarse sobre la comprensión de una no imposibilidad. Kant atribuye la no imposibilidad a objetos de conceptos que no contienen ninguna contradicción lógica, lo cual no afirma nada sobre su posibilidad, y no digamos ya sobre su realidad. En definitiva, tampoco el concepto, tan indeterminado, de cosas en general fuera de la esfera de las cosas fenoménicas podrá fundar una fe en Dios.

Los otros puntos de apoyo exigidos para la fe se pueden lograr, según Kant, no mediante la razón teórica, pero sí por medio de la razón pura práctica. Cómo ha de suceder eso, no es ciertamente algo directamente fácil de ver, pues el núcleo de la filosofía moral kantiana lo constituye su doctrina de la autonomía de lo moral, es decir, la doctrina de la libre gestación de las obligaciones éticas basándose únicamente en la relación del hombre consigo mismo, de modo enteramente independiente de Dios. Al inicio del escrito sobre religión se dice sobre

${ }^{1}$ La Crítica de la razón pura será citada siguiendo la paginación de la segunda edición (B), o en su caso la primera (A), las demás obras de Kant, por el contrario, según la Edición de la Academia: Kant's gesammelte Schriften, ed. Königlich Preußischen Akademie der Wissenschaften (y sucesores), Berlín [y otros], 21910 ss. (11900 ss.). Los números romanos designan el tomo, y los arábigos las páginas. 
esto de manera inequívoca: la moral «se basta a sí misma [...] en virtud de la razón pura práctica", y no necesita "para sí misma [...] la religión" (VI, 3); o también: el hombre no necesita "la idea de otro ser sobre él para conocer su deber, ni de otro motivo que el de la ley misma, para observarla" (ibíd.).

Sin embargo, con tales y tan decididas afirmaciones sobre la fundación de la moral no está captado todo aquello sobre lo que se puede y se debe reflexionar en el ámbito de la filosofía moral. La remarcada reflexión final de Kant es la reflexión sobre las consecuencias de la moral. Dicho sea de pasada, ese reflexionar no es, él mismo, una acción moral, por lo cual hay que llamarlo en cierto sentido "teorético". Para decir con toda brevedad las etapas más importantes de esta reflexión sobre las consecuencias que conducirán de hecho a Dios, comencemos con la idea de Kant de que el actuar moral de un hombre no conduce necesariamente a que ese hombre sea feliz. Dicho de una manera general: el nexo entre la moralidad y la existencia sensible del hombre no es el de la necesidad, sino el de la contingencia. Pero eso, que su proyecto de racionalidad encuentra su límite en una sensibilidad de la que no se puede disponer, es un escándalo desde el punto de vista de la razón pura práctica. Es el escándalo de que al hombre que se ha hecho digno de la felicidad no le viene de hecho la felicidad necesariamente. La razón pura práctica ha de exigir, pues, para su completa realización que "el sistema de la moralidad esté ligado [...] de manera inseparable con el de la felicidad" (KrV A809/B837); ella exige el "sistema de la moralidad que se premia a sí misma" (ibíd.). Pero no puede llevarlo a cabo en cuanto razón pura práctica del hombre. Y justamente por eso, "porque la capacidad del hombre no es suficiente para hacer que la felicidad en el mundo concuerde con la dignidad de ser feliz, [ha de] aceptarse un ser todopoderoso y moral como señor del mundo, bajo cuya providencia eso suce$\mathrm{da}$, es decir, la moral conduce inevitablemente a la religión" (VI, 8, Observación). El Dios aludido ocupa, como se ve, un lugar en un cálculo estrictamente racional, y con cierto derecho se le puede calificar como el Dios de la religión racional.

La cuestión sobre si se puede creer en ese Dios, es decir, si es posible estar convencido de su existencia con certeza subjetiva, permanece ciertamente abierta. Al menos se puede decir que es Dios según una idea, si bien necesaria, de la razón práctica, y por ello igual de problemático que todos los objetos de las meras ideas. Cabe decir: si el estado de cosas debe ser enteramente racional desde el punto de vista de la razón pura práctica, se debe aceptar a Dios necesariamente 
como garante de esa perfecta racionalidad; pero que ese estado de cosas sea enteramente racional y no sin esperanza por lo que respecta al sistema reunificado de moralidad y felicidad, nadie puede decirlo.

Lo que, según Kant, impele hacia la fe y es suficiente en ello es la circunstancia de que con la mencionada idea de la razón práctica - de manera distinta a lo que sucede con las ideas de la razón teórica- está ligado un interés predominante (uno general, no individual). Este interés en cuanto tal ha de ser considerado como significativo. La reflexión relativa a ello podría sonar así: no es posible que en relación al punto supremo de la autocomprensión humana, a saber, la autocomprensión moral, y cumpliendo las obligaciones que de ahí se desprenden, el camino conduzca a una absurda carencia de consecuencias; y no puede ser que la razón práctica sea simplemente engañada por su interés en la realización completa de ese modo de racionalidad propia de los hombres.

En otro lugar he defendido la tesis de que tales reflexiones conducen de hecho hasta el umbral de la religión, en el que se ha de creer como en una auténtica religión, pero no más allá. Para traspasar ese umbral, se necesita un acto de decisión. Pero aquí no vamos a ir más allá por ese camino, pues ya tenemos los presupuestos para estudiar el tema del servicio a Dios como un tema legítimo. También aquél que sostenga que Dios existe necesariamente sólo bajo una condición, a saber, bajo la condición «de que las cosas sucedan de un modo enteramente racional en el sentido de la razón pura práctica», puede reflexionar detenidamente sobre cómo el hombre serviría de la mejor manera a ese Dios.

En lo que sigue no se hablará meramente del Dios de la religión racional, al que conduce una reflexión sobre el perfeccionamiento del estado de cosas moral, sino también de Dios como él es tomado en diferentes religiones reveladas -en la terminología de Kant: en diferentes modos de fe histórica-, a saber, como un Dios que, sin una reflexión previa por parte del hombre, se ha comunicado sin embargo al hombre en el tiempo, entre otras cosas a través de mandamientos que atañen al modo como debe ser servido con propiedad, por ejemplo, por medio de especiales acciones de servicio divino cada siete días, los domingos. Tales mandamientos los llama Kant leyes estatutarias, que son leyes que la razón no puede desarrollar a priori desde sí. En el ejemplo del servicio divino dominical es fácil verlo, pues el número 7 no es para la razón más excelso que el 6 o el 8. Leyes estatutarias son pues leyes arbitrarias y contingentes para el hombre, $y$ reclaman su validez únicamente de que proceden del Dios revelado. 
En este lugar sólo se ha de traer a colación dos tesis principales, hacia las que apuntan las consideraciones que siguen. La primera dice así: lo que según la costumbre vale como servicio divino y descansa en leyes estatutarias, pero en parte también en la imaginación productiva humana, a saber, las acciones que conocemos como dirigidas especialmente a Dios en el marco de los diversos tipos de fe revelada, no puede valer ante la razón como verdadero servicio a Dios. La razón puede ciertamente dar a ese pretendido servicio divino en los modos de fe una interpretación en parte positiva, pero por otro lado ese servicio tiene muchas posibilidades de ser malinterpretado. En el caso de una tan fácil mala interpretación, ese servicio divino conduce a lo que Kant denomina como delirio religioso, que puede a su vez acrecentarse hasta sangrientos conflictos religiosos. La segunda tesis —ésta en relación con la religión racional- es: lo único que puede valer ante la razón como verdadero servicio divino no tiene un aparecer propio. Ningún fenómeno específico muestra ese servicio divino. Dicho de manera positiva, un verdadero servicio divino no es otra cosa que, según la expresión de Kant, una conducta moralmente buena. La conducta moralmente buena no aparece en lo fenoménico según los patrones del concepto teórico de fenómeno, por la simple razón de que la cualidad moral de las acciones no puede ser intuida exteriormente. Más importante para nuestro asunto es sin embargo que la conducta moralmente buena se agota en acciones relacionadas puramente con el hombre, hechas desde una disposición de ánimo moral, sin exigir por tanto ninguna acción dirigida especialmente a Dios.

Desde el punto de vista de la razón, las acciones especiales para el servicio divino que, yendo más allá del ámbito de acciones entre los hombres, pretenden tener una relación añadida con Dios, carecen "por sí de valor moral» (VI, 169). Más allá de la indiferencia moral, ellas conllevan incluso un peligro según Kant, a saber, el peligro del "antropomorfismo" (VI, 168) práctico. Se da un antropomorfismo práctico cuando acerca de Dios reflexionamos sobre cómo conseguir "ganarle de la manera más fácil para nuestro favor», y cuando con ello nos "creemos dispensados de los ininterrumpidos y penosos esfuerzos para trabajar lo más íntimo de nuestra disposición moral" (VI, 168-169), cuando albergamos la idea de que mediante un servicio dirigido directamente a Dios, que "no contradice la moralidad, si bien no contribuye a ellan (VI, 169), podemos lograr su favor. De esa manera representamos a Dios en forma humana, y quedamos por debajo de la representación moral y puramente intelectual de Dios, la única adecuada. Según los patrones de medida de la religión natural yace aquí el error de 
poder llegar a ser dignos de la felicidad, desde el punto de vista de Dios, por otras acciones distintas de las morales y poder después participar de la felicidad. Una relación con Dios así planteada representa, según Kant, una mera transposición de relaciones de sometimiento y sumisión, como se pueden encontrar entre los hombres. De estas relaciones es especialmente importante que la orientación que lleva a aceptarlas es la satisfacción de una necesidad, una felicidad en sentido puramente sensible. Así, Kant dice que "todo gran señor del mundo tiene una necesidad especial $[. .$.$] de ser honrado por sus súbditos y alabado por mues-$ tras de sometimiento, sin lo cual no puede esperar de ellos tanta obediencia a sus órdenes como él necesita para poder dominarlos" (VI, 103, 1, cursiva BD). Además todo hombre, «por muy racional que sea, encuentra siempre una inmediata satisfacción en los honores" (ibíd.). Una necesidad, por tanto, hay en todo gran señor del mundo, cuya satisfacción tiene el fin añadido de asegurar un dominio de otro modo quizás cuestionable; todos sentimos un placer ante los testimonios de respeto, que adulan nuestro amor propio. Todas estas cosas son signos pertenecientes a la esfera de la sensibilidad de los hombres, inapropiados por consiguiente para servir de distintivos de un concepto apropiado de Dios.

La consecuencia negativa más importante del concepto antropomórfico de Dios se da, sin embargo, cuando los súbditos toman conciencia de que los imperativos del gran señor, que sirve de prototipo para pensar a Dios, únicamente se fundan en su propio interés como señor, y son en consecuencia de origen heterónomo desde la perspectiva de los dominados. Este estado de cosas, traspasado a la esfera de lo moral, aniquilaría la moral. En ese caso se trata el udeber moral [...] como la gestión de un asunto de Dios, no del hombre» (ibíd.). Al hombre, por tanto, le tendrían que aparecer los imperativos morales como algo externo, no como los suyos, y en definitiva como aquellos de cuya coacción preferiría verse libre. Es del pensamiento de esa exterioridad en el origen de la obligación moral en Dios de donde surge, según Kant, «el concepto de una religión de servicio divino en vez del concepto de una religión pura moral" (ibíd.).

Hay que admitir aquí que también en la concepción de una religión puramente moral, los mandamientos morales son vistos como mandamientos divinos, pero con la decisiva diferencia de que allí el deber es «a la vez mandamiento divino" (ibíd.; cursiva $\mathrm{BD}$ ), por tanto no sólo mandamiento divino, sino también y sabre todo mandamiento bajo el cual ya se ha situado el hombre en la mera relación de sí mismo con la propia obligación. La concepción de la religión racional es, pues, enteramente consistente con la tesis de la autonomía de la 
moral. Según la religión racional, es cierto que cuando los hombres «cumplen sus deberes con los hombres (consigo mismos y con los otros)», deberes surgidos en su relación con la obligación propia, "justamente con ello también llevan a cabo mandamientos divinos", y que es incluso "absolutamente imposible servir más de cerca a Dios de otra manera» (ibíd.; cursiva BD).

La explicación que Kant ofrece de la idea de Dios antropomórfica rechazada, la que genera la fe eclesial en el servicio divino, está sostenida por una cierta idea provisional. Al hombre, en cuanto ser sensible y racional, le es propia una cierta debilidad, la de la uincapacidad en el conocimiento de las cosas suprasensibles ${ }^{2} \gg$ (ibíd.). El hombre, por los aspectos de la sensibilidad que siempre acompañan su comprensión de sí, no puede captar fácilmente la idea de un ser moral puramente racional sin el acompañamiento de ese aspecto. En principio, eso ha de ser posible según el concepto de una religión puramente racional. Ya el aspecto moral-práctico en la comprensión humana de sí mismo exige el conocimiento de algo puramente suprasensible. Pues desde nada situado en la esfera de la sensibilidad surge un imperativo moral, de manera que ya el conocimiento de la ley moral no es el conocimiento de un dato sensible. Tampoco hay a disposición nada dado internamente, algo así como un sentimiento moral. El conocimiento de la ley moral es conocimiento de un factum puramente racional, es decir, el conocimiento de algo autoproducido de manera puramente intelectual.

A pesar de su ocasional suavidad en relación con las debilidades humanas, Kant hace de las prácticas del servicio divino -en correspondencia con la calificación de "extremadamente peligrosas" (VI, 168) que aparece en otros lugaresla mayor parte de las veces la valoración más negativa, tanto si se trata de «festividades, incluso de juegos públicos" o "sacrificios" ("penitencias, mortificaciones, peregrinaciones, o cosas parecidas»). Observa con aversión que «los autocastigos [...] cuanto menos están dirigidos a la universal mejora moral del hombre, tanto más santos parecen» ser. Éstos parecen, «justamente porque no sirven para nada en el mundo, y sin embargo cuestan esfuerzo, estar dirigidos exclusivamente a dar testimonio de la entrega a Dios» (VI, 169). Cuando así ocurre, que a estas accio-

${ }^{2}$ La corrección del texto que hace la edición de la Academia, a saber, el cambio de "cosas sensibles", que es la expresión equivocada del texto original, por "cosas suprasensibles", es sin duda correcta. 
nes —que no tienen "por sí mismas ningún valor moral» embargo el "valor del fin mismo" (VI, 169-170), es decir, el valor de lo moral mismo, entonces ellas son a sus ojos expresión de un "delirio religioso" (VI, 170).

Ahora bien, las valoraciones ilimitadamente negativas de las acciones del servicio divino están bajo esta condición — si dichas acciones han de tener el valor del fin moral mismo-, de manera que bajo otras condiciones queda aún espacio para su aceptación, si bien limitada. Pues aquello que "no tiene ningún valor moral» puede no obstante tener un valor relativo "en cuanto medio", a saber, el de "elevar la facultad sensible de representación para que siga a las ideas intelectuales de fin, o reprimirla cuando pudiera actuar en contra de estas últimas» (VI, 169-170).

Para el hombre, en cuanto ser sensible, es completamente exigible que en situaciones moralmente relevantes no actúe como tal ser sensible, sino que sea capaz de seguir la idea intelectual de la moralidad, que la voluntad sea determinada y la acción llevada a cabo según los criterios de la moralidad, independientemente de cualquier preferencia sensible, mediante el juicio de la facultad práctica de juzgar. Para ello es necesario un distanciamiento con respecto a la facultad sensible de representación, que se funda en la necesidad individual corporal y apunta al fin privado de la felicidad, y por tanto está enfocada al placer. Por eso, las acciones de servicio divino, que no tiene per se carácter moral, pero sirven no obstante como medios para el fin de la moralización, no deben estar orientadas a la felicidad. Junto a los fines explícitos de felicidad en la satisfacción sensible de necesidades no deben estar actuando otros fines implícitos, como sería el fin de la repartición divina de felicidad post mortem como premio por las acciones de servicio divino. Apropiadas para ser medios de moralización son las acciones de servicio divino sólo cuando son acciones sin un objetivo desde el punto de vista de su lugar en el contexto de las necesidades sensibles. En cuanto que no apuntan per se a ningún fin moral, y como acciones carentes totalmente de fin, sólo les queda una cualidad puramente estética. Con todo, esa cualidad puramente estética puede ser considerada como orientada a lo moral, por cuanto que se halla en ella la elevación por encima del contexto de las necesidades sensibles. Acciones puramente estéticas cumplen la condición del distanciamiento respecto de las acciones motivadas de una manera meramente sensible, como también se exige de las acciones morales. Claro que con tal distanciamiento meramente negativo cumplen únicamente una condición necesaria pero no las condiciones suficientes para la moralidad. 
Ciertamente, desde el punto de vista de la religión racional sigue valiendo lo siguiente: «el verdadero (y moral) servicio de Dios, que han de realizar los creyentes como súbditos de su reino no menos que los ciudadanos del mismo (bajo las leyes de la libertad), es [...], así como éste, invisible, es decir, un servicio del corazón [...] y sólo puede consistir en la disposición de ánimo, en la observación de todos los deberes verdaderos como mandamientos divinos, no en acciones determinadas exclusivamente para Dios" (VI, 192). Si bien aquí las «acciones determinadas exclusivamente para Dios" están de nuevo excluidas del verdadero servicio divino - dado que éste ha de ser un servicio moral al hombre a partir de una disposición de ánimo moralmente buena, que es enteramente invisibleinmediatamente a continuación de lo citado atribuye Kant a la visibilidad de un servicio relacionado directamente con Dios una cierta y relativa legitimación: «sin embargo lo invisible necesita en el hombre ser representado por medio de algo visible (sensible), más aún, ser acompañado por éste con motivo de lo práctico, y aunque sea intelectual, hacerse por así decir intuible (según una cierta analogía)" (ibíd.). El hombre tiene, pues, una necesidad, o sea, una debilidad, de representarse sensiblemente lo invisible. En principio no deberá darse esa debilidad cuando finalmente deba sostenerse una religión racional pura, y con ella el verdadero y moral servicio divino, el que dirige su acción sólo a los hombres. No obstante, contra una debilidad fáctica temporal se puede echar mano de un remedio. La indicación de Kant, escasa en un primer momento, sobre el medio del representante sensible dice así: él es "un medio [...] sólo para hacernos representable nuestro deber en el servicio de Dios" (ibíd.). Por ello tendría que tratarse de algo visible que nos ponga ante los ojos de una manera enteramente universal que existe el deber moral en general, que es a la vez mandado por Dios. Dado que los mandamientos morales son puramente intelectuales, mediante eso visible no podrá ser hecho sensible ningún mandamiento moral en el sentido literal de una presentación. Se habría de considerar una especie de señal sensible de que se da ese deber en la esfera invisible de la intelectualidad pura de la razón práctica. Sin embargo, parece que se dice muy poco con el recurso de los signos. En ese caso, también los signos de la escritura, mediante los cuales pueden ser llevados al papel los mandamientos morales, podrían valer como las cuestionables sensibilizaciones. Sin embargo, los meros signos - dice Kant en la Critica del Juicio-no contienen «nada que pertenezca a la intuición del objeto" $(\mathrm{V}, 352)$. Una afirmación de Kant que va un poco más allá acerca de la sensibilización de lo invisible del servicio de Dios puramente moral, que es directamente un servicio al hombre, reza así: eso invisible, «si bien es intelectual", puede «hacerse, por decirlo así, intuible (según una cierta analogía)» (VI, 192). 
Sensibilización «según una cierta analogía» es un modo enteramente especial de sensibilización, que ha de ser distinguido de otros modos. Kant acierta en esas distinciones de la manera más expresiva en el $\$ 59$ de la Crítica del Juicio. Con las explicaciones que da ahí viene a ser claro que en una sensibilización desde la analogía no puede tratarse de una sensibilización mediante ejemplos, la cual está subordinada a los conceptos empíricos; tampoco de una sensibilización esquemática, que es la de los conceptos puros del entendimiento. La sensibilización de los conceptos de razón se declara como totalmente imposible, por lo que su objeto habrá de permanecer completamente invisible. Pero hay que observar que sólo se declara esa imposibilidad bajo la condición de que se trate de «la realidad objetiva del concepto de razón [...], y en concreto con motivo del conocimiento teórico de la misma» $(\mathrm{V}, 351)$.

Exposición de los conceptos de razón -en nuestro caso del servicio divino invisible, verdadero y moral - es posible sin embargo, al lado de las excluidas formas directas de sensibilización, de una forma indirecta, a saber, como sensibilización simbólica. En eso se sigue dando que el tipo de visibilidad que puede tener un concepto de la razón en el modo de un símbolo es distinto al que se exige en el caso del conocer teórico, es decir, sigue siendo verdadero que "ninguna intuición sensible puede ser adecuada" (ibíd.) a un concepto de razón. Pero a pesar de toda inadecuación hay, según Kant, un modo simbólico de visibilidad, que se ha de llamar estético. Éste es obtenido «mediante una analogía» (V, 352).

El procedimiento de la analogía para la producción de símbolos lo considera Kant como "aún poco investigado" (ibíd.). Sin embargo, sus propias afirmaciones son elocuentes y con posibilidades de desarrollo, y podrán ser finalmente aplicables a nuestro problema del servicio divino. En el procedimiento analógico se da una «transposición de la reflexión sobre un objeto de la intuición a un concepto enteramente otro, al que quizás nunca pueda corresponderle una intuición directa» (V, 352-353). Una segunda afirmación fundamental - desarrollada al hilo del ejemplo de que un molinillo puede servir como símbolo de un Estado monárquico dominado por una única voluntad absoluta - dice que "entre un Estado despótico y un molinillo" no hay "ciertamente ninguna semejanza», "pero sí entre las reglas para reflexionar sobre ambos y su causalidad" (V, 352). De ello se ha de retener que ambas analogías son y serán enteramente diferentes en cuanto al contenido. El molinillo no es en ninguno de sus elementos un Estado despótico, pero ambos permiten que se reflexione de la misma manera acerca del modo de obrar. 
En el contexto de la Crítica del Juicio, que es relevante no sólo de manera comparativa por lo que se refiere al problema del servicio divino, sino también en cuanto al asunto mismo, el símbolo del que se trata fundamentalmente y que cumple con las condiciones mencionadas de la simbolización es lo bello. Según Kant, lo bello es símbolo de la moralidad. La concordancia de la reflexión sobre lo bello con la reflexión sobre la moralidad, que incluso es exigida, puede expresarse así con la ayuda de Kant: de igual modo que en el caso de la autocomprensión moral, también en el del enjuiciamiento de lo bello el ánimo es "consciente a la vez de un cierto ennoblecimiento y elevación sobre la simple receptibilidad de un placer a través de las impresiones sensibles", y aprecia "otro valor también según una máxima parecida de su facultad de juzgar» (V, 353). Por lo demás, Kant conserva de esa concordancia que las condiciones de la posibilidad del enjuiciamiento de lo bello no proceden de la experiencia, que se trata de un enjuiciamiento autónomo como en el caso de lo moral (ibíd.). Finalmente, Kant señala que la analogía de lo bello y de lo moral es utambién habitual para el entendimiento común", lo que se muestra en que es enteramente corriente calificar a los objetos bellos con denominaciones "que parecen tener a su base un enjuiciamiento moral». Por ejemplo, los llamamos «majestuosos» o "suntuosos» (V, 354).

Con las consideraciones que acabamos de hacer sobre la analogía o, en su caso, la simbolización en un primer momento de carácter formal y después en cuanto a su contenido entre lo bello y lo moral, nos hemos alejado sólo aparentemente de la cuestión relativa al escrito kantiano sobre religión, sobre cómo hay que entender la relación, apenas indicada, entre el servicio divino verdadero y moral y su sensibilización "según una cierta analogía». Para exponer la tesis en vista a una explicación más detallada, hemos de constatar lo siguiente: la justificación relativa que atribuye Kant a lo que, corrientemente y sin más calificación, se llama servicio divino -a saber, las acciones dirigidas directamente a Dios en ceremonias y cosas por el estilo- consiste en que este servicio puede ser interpretado como un servicio divino simbólico, y en concreto simbólico de la misma manera que es pensado mediante la analogía entre lo bello y lo moral. La praxis denominada, corriente y sencillamente, servicio divino no es, por consiguiente, el verdadero servicio divino moral, así como un molinillo no es un Estado despótico. Esta praxis sigue siendo per se moralmente indiferente, pero puede valer sin embargo, en cuanto praxis realizada según ideas estéticas, como símbolo del verdadero servicio divino moral. Con tesis como éstas puede ser caracterizado lo más que Kant puede sacar del servicio divino mediante las acciones directamente referidas a Dios. Pero eso no deja de ser algo, como puede mostrarse de una manera un poco más particular. 
En el lenguaje de los criterios desarrollados puede decirse que el objeto de la intuición, sobre el que se lleva a cabo la reflexión que cabe trasponer después al concepto, enteramente distinto, del verdadero servicio divino moral, es el servicio divino estéticamente simbólico. Si ahora nos preguntamos qué contiene el servicio divino simbólico que sea apropiado para la exposición indirecta del verdadero servicio divino moral, o si, en su caso, se pregunta qué reflexión determinada sobre el servicio divino simbólico puede ser transferida al verdadero servicio divino moral, entonces se ha de contestar algo así: el servicio divino estéticamente simbólico contiene acciones sensibles, sobre las que en un punto esencial se ha de pensar como sobre las acciones morales del verdadero servicio divino, a saber, que consta de acciones que no están referidas a ningún fin sensible. Justamente eso, separarse de la orientación sensible de los fines dirigidos a la satisfacción de necesidades, es también una condición necesaria (aunque no suficiente) para las acciones morales del verdadero servicio divino, que es en efecto de modo directo - lo que no hay que olvidar nunca- un servicio a los hombres. Desde el punto de vista de la sensibilidad, es decir, de la satisfacción de necesidades patológicas de felicidad, las acciones del servicio divino simbólico son acciones vacías y sin sentido. Son acciones producidas por el hombre en virtud de su capacidad para la autodeterminación estética. Por naturaleza no se producirían. En cuanto acciones vacías tampoco son acciones morales; carecen enteramente de fin, por tanto no sólo no tienen ningún fin sensible, sino tampoco un fin moral. Y sin embargo, su carácter de vacío puede interpretarse, bajo el punto de vista de los fines sensibles, como apertura a la esfera de la determinabilidad moral. Gracias a la liberación respecto a los fines sensibles, queda abierta la posibilidad de sustitución por fines morales.

Las acciones estéticamente simbólicas en cuanto tales quedan por debajo de las exigencias morales. Se entiende que las dos partes de la analogía no coinciden, no son consideradas como idénticas. Repito: así como un molinillo no es un Estado despótico, tampoco un servicio divino simbólico es el verdadero moral. El simbólico sigue siendo per se moralmente indiferente.

Y sin embargo, aunque mediante las acciones simbólicas no se realizan fines morales, pueden ser consideradas no obstante como dirigidas hacia tales fines potenciales, en cuanto que por medio de ellas queda ya cumplida la condición de eliminar motivos sensibles. Así entendidas, las acciones simbólicas están por encima de la sensibilidad, si las valoramos estéticamente, pero por debajo de la moralidad. Están situadas a medio camino hacia la moral. Dependiendo de que el 
punto de vista sea el de que está por detrás de la moralidad o por encima de la sensibilidad, se puede poner el acento en que tienen meramente un valor estético, o que tienen no obstante valor estético.

Hay, claro está, en la esfera de lo estético una pluralidad de posibilidades de diferenciación bajo el punto de vista del refinamiento civilizatorio. Kant diagnostica una "enorme distancia en las maneras" entre un "sublimado puritano en Connecticut" y un "vogul totalmente sensitivo, que se pone por la mańana la garra de una piel de oso sobre la cabeza con la breve oración: 'no me mates'” (VI, 176). Sin embargo esa enorme distancia es únicamente una distancia en valores estéticos. La distancia en el valor moral no puede ser acortada mediante un mayor refinamiento estético, porque el valor moral es diferente del estético en especie y no en grado, dado que los valores morales han de ser puestos por medio de un acto moral, enteramente particular, y no mediante actos estéticos. Admitir un acercamiento gradual en virtud de un refinamiento civilizatorio conduce —en perjuicio de la moral — directamente al esteticismo.

Con lo dicho puede afirmarse que queda explicado lo que Kant expresa repetidamente, pero apenas dilucidado cómo lo que corrientemente se llama servicio divino y, visto con precisión, es servicio divino simbólico, puede servir como medio para el verdadero servicio divino moral, que consiste sencillamente en acciones morales entre los hombres. Kant reconoce a veces que este medio es «un medio no prescindible" (VI, 192). Ciertamente, con ello no se quiere decir que sea algo estrictamente imprescindible, lo que permite que esa afirmación sea compatible con las que proyectan el estado final (quizás lejano) de una religión racional moral enteradamente realizada sin ningún servicio divino simbólico.

Enteramente rechazable en la relación de ambos tipos de servicio divino es para Kant el caso de que, a la inversa, el servicio divino en cuanto conducta moral pudiera estar subordinado como un medio para el fin del servicio divino, el único que sería realmente grato a Dios, y que se referiría especial y exclusivamente a Dios. El valor de servicio divino de la conducta buena moral no tiene semejante carácter mediador y de rodeo: «que el servicio moral a Dios (officium liberum) le agrada a él directamente, es evidente de por sí» (VI, 177). Ese servicio moral, y con ello referido a los hombres, que agrada directamente a Dios, es más bien por su parte condición suprema para una justificación relativa que Kant, como se ha visto, da al servicio divino simbólico relacionado exclusivamente con Dios. Si éste no fuera condición suprema, es decir, si el servicio divino de las acciones de vene- 
ración moralmente indiferentes pudiera «ser considerado por si como el único que agrada a Dios" (ibíd.), entonces se seguiría una consecuencia imposible de aceptar para la razón pura práctica: "pues entonces nadie sabría qué servicio sería preferible en un caso concreto" (ibíd.). En la concreción de un caso cualquiera eso significaría que podría ser dudoso si, en el caso de una exigencia aguda y moral por estar en peligro un hombre, se debe cumplir esa exigencia de servicio divino moral, o no más bien continuar con una ceremonia de servicio divino en curso a fin de agradar más bien a Dios de ese modo.

El modo simbólico de servicio a Dios, justificado ante la razón provisionalmente como medio para elevarse por encima de la sensibilidad y, con ello, como un paso hacia la moralización, es entonces según Kant un "medio muy expuesto al peligro de la mala interpretación» (VI, 192); sobre todo cuando no está comprendido como un servicio divino meramente simbólico. Entonces «a causa de un subrepticio delirio, se le considera fácilmente como servicio divino, y así se le llama también comúnmente" (ibíd.). Por consiguiente, cuando al servicio divino simbólico se le quita lo que le caracteriza, es decir, la descrita referencia analógica indirecta a la moral, y se le declara directamente en cuanto tal como perteneciendo a la praxis moral, o bien se le tiene" por un "medio [...] en sí agradable a Dios" (VI, 193), eso es según Kant "una fe fetichista" (ibíd.). Por fe en fetiches se ha de entender más específicamente la autopersuasión de que sólo "creyendo firmemente" y "ligando ciertas formalidades" (ibíd.) a esta fe, puede producir algo querido, o sea, la elevación del propio estado moral. Tales autopersuasiones las atribuye Kant al hombre sensible, que procura, "con perezosa confianza en soñadas gracias", "liberarse a hurtadillas de la penosa condición" (ibíd.) de que únicamente por medio de las propias acciones morales, realizadas en buena disposición de ánimo moral en el mundo de los hombres, puede alcanzar un status de dignidad más elevado.

Según Kant, la extendida ilusión de considerar como servicio divino algo que no lo es, queda especialmente expresada en la oración realizada como un medio para alcanzar la gracia. La fe en un medio de gracia, es decir, la creencia del hombre en disponer de medios para poder influir sobre Dios a fin de ser purificado de su culpa por él como una continuación directa de su actuar, o a fin de superar la propia cualidad moral para la vida futura, la coloca Kant, junto con la creencia en milagros y en misterios, entre las creencias ilusorias (cf. VI, 194). Las expresiones, tantas veces repetida por Kant, de delirio, locura, fe ilusoria, de estar poseído, de exaltación, de superstición, para caracterizar una falsa idea de Dios y una relación con Dios que la razón excluye, pueden parecer demasiado agresivas, como cuando 
se trata de la oración corriente, que, si bien no es útil, tampoco podría ser considerada como perjudicial. Semejante visión significaría para Kant, en efecto, pretender ocultar su peligro. A sus ojos - aunque sea algo corriente e inocentemente irreflexivo- el rezo realizado como medio de gracia es de hecho peligroso, a saber, medido según el patrón de la razón pura práctica, que exige una praxis moral desde la determinación autónoma del hombre por sí mismo y empleando sus propias fuerzas. Según esta medida, con la oración literalmente "no se ha hecho nada" (ibíd.), es decir, no cabe reconocerla como praxis, sino como expresión de la razón perezosa, y no puede, por consiguiente, "tener referencia alguna a la complacencia divina" (VI, 196). Apenas es preciso añadir que, en esas circunstancias, no puede haber ningún deber de orar.

En medio de tantas críticas al rezo, puede servir de suavización eventual indicar que Kant atribuye también a la oración una función positiva, si bien una muy limitada, relativa, provisional y bajo condiciones. Finalmente, Kant habla, diferenciándolo del rezo mismo, de un espiritu de la oración, que tiene su consistencia ante la razón pura práctica, pero que apenas estaría ya en relación con lo que llamamos el fenómeno del orar.

Pero por ahora hemos de continuar con la crítica a la oración. Aparte del rezo hasta ahora tematizado y rechazado como una petición de mejoramiento moral por Dios, rezar puede ser, así dice Kant, también "efecto de una necesidad sentida y meramente animal» (VI, 195, Observación), como cuando se pide por el pan de cada día. Entendido como efecto de una necesidad animal, no es propiamente ninguna petición expresada por nosotros en nuestra calidad personal, sino, dice Kant, "más una confesión de lo que la naturaleza quiere en nosotross (ibíd.).

También esto vuelve a ser para Kant una «ilusión presuntuosa" (VI, 196, Observación), exigir a Dios mediante el rezo una intervención en las circunstancias de nuestra vida "con vistas a una ventaja actual para nosotros", una exigencia que no rara vez se eleva con «la machacona insistencia del ruego» (ibíd.). Es la ilusión de que a Dios hay que exigirle que vele por la conservación de nuestra existencia empíricamente corporal y la realización de sus intenciones, que son todas ellas intenciones de felicidad, y que utilice el medio de una intervención sobrenatural no ya para un fin moral (lo que sería igualmente algo cuestionable), sino para nuestros deseos de placer. $\mathrm{Al}$ poseído por semejante ilusión le acusa Kant de tener una idea muy disminuida de Dios, y piensa contra 
él que quizás pueda "compaginarse mejor" con la sabiduría de Dios "dejarle morir hoy" (ibíd.). La prosecución de las intenciones de felicidad o de placer es para Kant - que a menudo ha sido tenido falsamente por un enemigo de la sensibilidad- enteramente "buena" en el sentido de "no rechazable" (VI, 58); sin embargo, ella es únicamente un asunto del hombre natural, es decir, del hombre ocupado por sus necesidades animales. Él mismo ha de procurarse su satisfacción, apoyándose en consideraciones de prudencia. A un rezo que pida a Dios esa satisfacción podría faltarle incluso, según Kant, la "capacidad de ser atendido" (VI, 196, Observación), lo que significa que el Dios pensado según nuestra idea de Dios no pudiera oírlo en absoluto. No podemos «tener con certeza por atendible ninguna oración que tenga un objeto no moral" (ibíd.). Hay que advertir en este lugar, pero también problematizar con Kant, que la oración de contenido moral, dirigida al Dios pensado como instancia moral, cumple la condición de ser atendible por principio. Sin embargo la objeción que él pone inmediatamente contra esa relación con Dios reza así: «Incluso si el objeto [de la oración] es moral, pero sólo posible por medio de una influencia sobrenatural (o al menos nosotros la esperamos sólo así, porque nosotros mismos no nos queremos esforzar en ello [...]), es muy incierto que Dios vaya a encontrar conforme a su sabiduría completar nuestra carencia (autoculpable), y más bien se tienen razones para esperar lo contrario" (ibíd.).

¿Cuál es entonces la oración que acaba de ser anunciada como aceptable para la razón, la oración, por así decir, más cercana a la religión racional? Para caracterizarla de la manera más expresiva, pero todavía de un modo no comprensible: es la oración que formula expresamente el espíritu de oración, que lo reviste con "palabras y fórmulas", "aunque sólo sea internamente» (VI, 195). Por supuesto que hay que explicar lo que pueda ser "espíritu de la oración». Según Kant es el «deseo de corazón de ser agradable a Dios en todo nuestro hacer y omitir, es decir, la disposición de ánimo que acompaña todas nuestra acciones, de llevarlas a cabo como si ocurrieran en servicio de Dios" (VI, 194-195). Desear para sí el poder actuar de manera agradable a Dios no conduce más allá del marco de la religión racional, pues lo que ésta exige de suyo, a saber, un actuar moral, es pensado en ella como expresión de obligación autónoma y como seguimiento de un mandato moral que nos hemos puesto nosotros mismos y a la vez como algo que no se aparta lo más mínimo de una obligación divina, de tal manera que el deseo de alcanzar a llevar una vida moral puede ser expresado al mismo tiempo como el deseo de lograr una vida que agrade a Dios. Si el deseo se articula de esta segunda manera de un modo expresado en palabras y fórmulas, de manera 
externa o interna, entonces se trata de una oración que expresa el espíritu de la oración. Pero incluso esa oración no es praxis moral real. Es algo más que aquella oración que acosaba a Dios pidiéndole una intervención sobrenatural, es por tanto algo más que no hacer nada, porque, como piensa Kant, es capaz de fortificar la disposición de ánimo moral del que ora, mas esa fortificación es sólo un presupuesto para la praxis propiamente dicha, y aún no esa praxis misma. Según Kant, puede «conllevar como mucho el valor de un medio para la repetida vivificación de esa disposición de ánimo en nosotros" (VI, 195-196). Ahora bien, dado que ese rezo especial es un medio ciertamente potencial, pero no necesario, para la vivificación de la disposición de ánimo moral, no puede, como cualquier rezo fáctico, "ser un deber para todo el mundo" (VI, 196-197). Pues un "medio únicamente" puede "serle prescrito [...] a aquél que lo necesita para un cierto fin" (VI, 197); pero "no todo el mundo, ni mucho menos, tiene [...] necesidad ese medio" (ibíd.).

Pero suponiendo que alguien tuviera necesidad de la oración y la practicara, ¿cómo habría que caracterizar esto más detalladamente? Evidentemente, en el caso de una acción de orar, cuyo fin es el de vivificar por medio del rezo mismo la propia disposición del ánimo moral, se trata de un actuar sobre sí mismo, de un acto de autorreferencia. Cuando rezar es, según las palabras de Kant, una especie "de conversación [...] propiamente consigo mismo" (ibíd.), entonces claramente deja de ser aquella oración hecha de manera temática y originaria, que quería abrir no una relación consigo mismo, sino con algo ajeno, con Dios, un relación por tanto transcendente. En el caso de que la oración -autorreferencial, orientada a la propia disposición de ánimo moral - estuviera dirigida a Dios, este Dios tendría que estar ubicado enteramente en la inmanencia del que reflexiona, como ocupante ficticio — por así decir - de un extremo de la relación, que en el pensamiento del monólogo debe ser pensado, puesto que también una conversación de este tipo requiere el pensamiento de una diferencia entre el que habla y el que escucha. Y así Kant habla de la vivificación de la propia disposición de ánimo moral «mediante la idea de Dios» (VI, 195, Observación). Los objetos de las ideas, sin embargo, son inmanentes en cuanto que son entes de razón, de manera que el rezo que, según Kant, sigue siendo legítimo no posee en último término ninguna dimensión transcendente.

Por lo que respecta a la cualificación moral de la oración inmanente y de la transcendente, Kant otorga incluso una ventaja a la inmanente. Por sus características morales puede realizarse con entera rectitud, porque no implica la arro- 
gancia de "poder asegurar con completa certeza" (ibíd.) la presencia actual de Dios, lo que significaría asegurar que se reza ahora a un Dios efectivamente presente, que me escucha literalmente. Dado que deja tras de sí todas las precauciones críticas con respecto a una posible relación con lo suprasensible, la oración transcendente atrae hacia sí la sospecha de falta de rectitud y de hipocresía. Toma, en virtud de su "forma de alocución [...], ese objeto supremo como personalmente presente, o al menos se pone (incluso interiormente) como si estuviese convencido de su presencia» (ibíd.). Si alguien que ora en dicha forma de alocución diera un paso hacia atrás, hacia la reflexión crítica, entonces tendría que dar cuenta de si tiene suficientes intuiciones internas (o bien externas) de Dios. La imposibilidad objetiva de intuiciones internas y externas de lo divino pertenece en Kant a los resultados capitales de la Crítica de la razón pura.

Al hombre que se le encuentra orando en voz alta o simplemente en el «ademán" de orar, Kant le atribuye -y en este pasaje es algo más suave- un "pequeño acceso de locuram, pues tal hablar y gesticular es propiamente sólo posible a aquel «que tiene fuera de sí alguien ante la vista, lo cual no es el caso en el ejemplo adoptado" (ibíd.).

En el Conflicto de las Facultades, Kant expresa, no casualmente en un contexto donde trata las sectas pietistas, su crítica a la oración de la manera más polémica. Aquí se pregunta, en relación con la "oración ferviente y incesante», practicada en esas sectas, "en qué medida se la quiere hacer valer como una acción" (VII, 56), y respecto a un exigido "trato continuo con un espíritu celestial», con el que habría que hacer "precisamente [...] una alianza" (VII, 56-57), qué "fisonomía nacional» (VII, 57, Nota) tendría todo un pueblo educado por esas sectas. Dicho pueblo se distinguiría, según su respuesta, de «otros pueblos cultos y despiertos", no a su favor, por "rostros benditos", y ofrecería un «dibujo de la piedad en caricatura" (ibíd.). Eso se puede explicar viendo que "las impresiones sobre el ánimo, muchas veces repetidas, sobre todo las antinaturales, se exteriorizan en gestos y en el tono de voz, y se convierten en aspecto físico, y finalmente en rasgos faciales estables" (ibid.).

De la oración que pretende el trato fáctico con Dios, una alianza directa con él, debemos retornar de nuevo al espíritu de la oración, que no ha sido completamente investigado. Para una más detallada elucidación, Kant se apoya por lo demás en el "Maestro del Evangelio" (VI, 195, nota). Hay que notar que él puede hacerlo sin problema porque concede a la doctrina cristiana un núcleo 
que no se diferencia de las doctrinas de la religión filosófica racional, ya que no expresa otra cosa que una moral pura. Basándose en esa identidad de las doctrinas, no es por supuesto exigible que sea el «Maestro del Evangelio» aquél que nos haga conocer el espíritu de la oración, pues la razón pura práctica de cada uno ha tenido que poder desarrollarlo también a partir de sí misma. Sin embargo, por otra parte, tampoco ha de ser discutido que también el «Maestro del Evangelio" lo ha desarrollado.

Según la fórmula, alabada por Kant como acertada, del “Maestro del Evangelio», el espíritu de la oración no contiene sino el "propósito de una conducta moralmente buena, que, ligado a la conciencia de nuestra fragilidad, alberga un deseo constante de ser un miembro digno en el reino de Dios» (ibíd.). De esta fórmula Kant ofrece una explicación, cuyas ricas consecuencias pueden ser fácilmente no percibídas, por estar un tanto confusamente formuladas. Afirma que esta fórmula hace que "ésa» - aludiendo a la oración- «y con ello también ella misma (en cuanto letras) sean prescindibles» (ibíd.). Donde el espíritu de la oración, que puede ser desarrollado en la autorrelación moral del hombre, es decir, sin tener que entrar en una relación transcendente con Dios, está activo como buena disposición de ánimo moral, allí puede "desaparecer finalmente" (VI, 197) toda letra, es decir, todo rezo que se exprese intencionadamente como fenómeno, según Kant vuelve a decir. La articulación expresa de una oración en cuanto tal - ya sea la articulación de la fórmula del mismo espíritu de la oración - o sea, el rezo fáctico en palabras y fórmulas, el que se manifiesta en el fenómeno externo o sólo en el interno, no es pues necesario, según Kant, y sin embargo el hombre puede encontrarse en el espíritu de la oración.

Aquella articulación de la oración en cuanto tal no puede ser pensada como agradable a Dios, porque no es ninguna praxis en el sentido propio de la palabra, es decir, ninguna praxis moral. Conforme a lo dicho, por tanto, podrían desaparecer del mundo todos los rezos hasta ahora realizados o por realizar, y el mundo no tendría que ser pensado como moralmente peor, ni siquiera como yendo a menos religiosamente. Kant da incluso a conocer su valoración: el estado moral del mundo podría ser mejor sin la «letra», o sea, sin el fenómeno interno o externo del rezo: "pues ésta [la letra] debilita más bien el efecto de la idea moral, como todo lo que está indirectamente dirigido a un cierto fin" (ibíd.). Por qué actuar indirectamente sobre el fin de la moralidad, es aquí la cuestión, cuando se puede actuar directamente sobre él. $Y$ ese actuar directo puede ser incluso a la vez un actuar religioso en el sentido de la religión moral racional, 
cuando un hombre sin ninguna facticidad de rezos está sin embargo en el espíritu de la oración. Para ello ha de hacerse sencillamente el propósito de llevar una vida moralmente buena, ser consciente de su "fragilidad" moral, y tener el deseo (no manifestar la petición) de ser miembro en un reino moralmente perfecto. De ese reino él sabe también que los hombres no lo podrán realizar. Tal conciencia la llama Kant "disposición de ánimo moral (animado únicamente por la idea de Dios)" (VI, 195-196, Nota). A todos estos modos de conciencia (hacerse el propósito, tener el deseo, etc.) se ha de añadir necesariamente aún el actuar. Una disposición de ánimo moral en el espíritu de la oración sólo tiene valor como "disposición de ánimo que acompaña nuestras acciones" (VI, 195), nunca como tal y sin acompañar una acción.

La reducción expuesta de la oración efectiva y del rezo efectivo al espíritu de la oración, enteramente invisible, de la religión moral racional puede ser, por lo demás, considerada como un accesorio prescindible para un contenido religiosamente importante. Como consecuencia de esa reducción se desprende, entre otras cosas, que el estado religioso de un hombre o de una sociedad de hombres no puede ser captado en la variedad de prácticas religiosas visibles, empíricamente dadas. Ni un pequeño número de tales prácticas, realizadas de manera expresa, indica la no religiosidad de una sociedad, ni a la inversa, un gran número su especial religiosidad.

Según la religión racional, únicamente se pone como deber una conducta moralmente intachable en la inmanencia de las relaciones entre los hombres. $\mathrm{La}$ conducta moral, sin más aditamento, es para ella en cuanto tal servicio divino, por eso, desde su punto de vista, también aquel hombre moralmente intachable sirve a Dios y es agradable a él aun cuando nunca sea capaz de realizar aquella reflexión teórica que conduce a la religión racional. Él sirve a Dios en ese caso de manera, por decir así, objetiva, aunque no subjetiva. Pero también aquel moralmente bienpensante, que ha podido llegar al conocimiento de la reflexión y seguir sus conclusiones, pero no hasta el propio convencimiento de la existencia de Dios como legislador moral adicional y como garante de una perfección moral en la totalidad de una unión conseguida entre la felicidad y el ser digno de la felicidad, o que incluso contradice estas conclusiones, es, desde el punto de vista de la religión racional, agradable a Dios y está a su servicio en la medida en que es moralmente intachable. Pues aquella reflexión es teórica, es decir, una mera reflexión sobre el contexto general de la situación moral del hombre. No hay una obligación moral de llevar a cabo esta reflexión teórica, por eso no 
puede verse tampoco ningún defecto moral en desviaciones teóricas del concepto de la religión racional, en todo caso el defecto de inteligencia de no aceptar unà teoría concluyente. Se puede considerar, desde el punto de vista de la religión racional, que todo aquél que cumple la condición de la moralidad satisface objetivamente sus exigencias, aun cuando se desvíe teóricamente. Comprendidos en este agrado a Dios, al que tiende la religión racional, están por tanto también - presuponiendo siempre la conducta moralmente buena- un agnóstico e incluso un ateo, al que únicamente se le puede achacar el dogmatismo teóricamente insostenible de pretender un conocimiento transcendente respecto a la no existencia de Dios. Al Dios pensado en el concepto de la religión racional sólo le puede resultar importante y agradable el actuar moral. Si él premiara con su agrado también la más elaborada teoría de los hombres sobre él, entonces ya no sería pensado meramente como legislador moral, sino — de nuevo de manera antropomórfica - un poco elitista y vanidoso.

Así como no cabe pensar que él premia una reflexión moralmente indiferente, tampoco se puede pensar una recompensa por las prácticas, en el mejor de los casos, premorales de un servicio divino especialmente dedicado a él. Por el contrario, respecto a esas prácticas es recomendable un examen conforme a los patrones de la razón pura práctica. Éste, en el caso favorable, puede dar como resultado que las acciones expresas de servicio divino son practicadas con la conciencia de que son acciones simbólicas, moralmente indiferentes per se, pero con un utilidad limitada en cuanto medio para la moralización. En los casos menos favorables, que serían los más abundantes - pues casi en ninguna parte los practicantes entienden el servicio divino como acción simbólica-, las prácticas expresan el autoengaño y la ilusión de tener una relación familiar de comercio con Dios y adquieren el carácter de acciones sustitutorias de la moral. Pero el caso catastrófico para la razón pura práctica es aquel -y de nuevo se vuelve a observar en nuestro tiempo- cuando, apelando a una pretendida alianza con Dios, se cometen acciones antimorales, asesinato, terrorismo, guerra, como realizaciones de indicaciones divinas, por tanto como servicio divino. Para acabar, respondamos de nuevo a la pregunta del título de manera positiva: servido quiere ser el Dios de la religión racional únicamente mediante una conducta moralmente buena entre los hombres; por ninguna otra cosa. Dios mismo puede estar expresamente en el pensamiento durante semejante conducta, lo cual presupone una reflexión filosófica, pero no es necesario, y la conducta le puede agradar igualmente. 